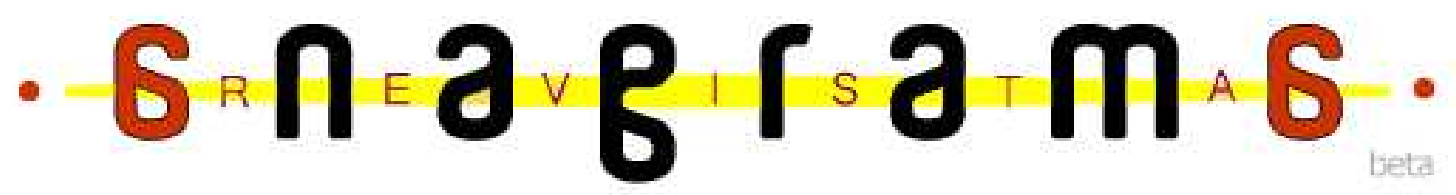

A Emoção Fabricada: uma análise do discurso criado para emocionar na propaganda do Banco Itaú

\section{Maiana Rodrigues Melo}

Mateus Santos da Silua

Uilmária Bispo dos Santos ${ }^{1}$

\section{Resumo}

Este artigo busca analisar como são criados os anúncios publicitários do Banco Itaú e evidenciar o uso do discurso emotivo como forte estratégia de marketing na fabricação da emoção do consumidor, conduzindo-o ao consumo do produto pelo viés emocional. Para uma maior compreensão e identificação do discurso emotivo presente nos respectivos anúncios, realizamos uma análise discursiva tomando como base teórica os artigos "A patemização na televisão como estratégia de autenticidade" de Patrick Charaudeau, os pressupostos de Martine Joly, além de Maria Aparecida Lino Pauliukonis em seu escrito sobre persuasão e sedução no discurso publicitário. Analisamos os modos de organização empregados no discurso, bem como as mensagens plástica, icônica, e, sobretudo, linguística, utilizadas como ferramentas criadas para persuadir, buscamos com isso, compreender a influência da composição imagética na encenação discursiva. A análise do discurso é um recurso metodológico que possibilita, assim, a explicitação de algumas formas de patemização, tentando recuperar pistas da emoção em certos dados lexicais e sintáticos e no uso de termos comuns de uma cultura. Acredita-se que através deste trabalho se desperte um maior senso crítico quanto ao poder de persuasão da publicidade que, por vias psicológicas, é capaz ditar as necessidades de consumo do público.

Palauras-chave: Emoção; Discurso; Patemização; Persuasão; Consumo.

\footnotetext{
${ }^{1}$ Alunos do curso de Comunicação Social - Rádio e TV na Universidade Estadual de Santa Cruz - UESC. Orientação: Profa. Ms. Sylvia Maria Teixeira.
} 


\section{IกTRODUÇก̃O}

Nos últimos anos as empresas de marketing e propaganda têm recorrido à psicologia em busca de novas técnicas que conduzam a um resultado eficaz no papel de persuasão do consumidor.

As intenções são bem definidas e estão espalhadas por toda a composição do que Martine Joly (1994) chama de imagem retoricizada. Para Durand (1996), a imagem retoricizada (figuras de retórica na imagem publicitária) possui a função de provocar o prazer do telespectador permitindo-lhe sonhar com um mundo onde tudo é possível.

O objeto estudado neste trabalho são dois anúncios, em forma de imagem estática (ver anexo) que compõem as campanhas publicitárias: "Colo" e "Dupla Dinâmica", criados pela agência de marketing e propaganda DM9DDB para um seguro de vida, serviço oferecido pelo banco Itaú, publicados em outubro de 2010 através de folders, disponibilizados nas agências bancárias Itaú e em sites publicitários na Internet. Ambos se utilizam do discurso emotivo associado à imagem de crianças detentoras de padrões de plasticidade e estereotipia como formas de agenciamento de emoções. Os anúncios primam pelo uso de textos fluidos e imagens visualmente confortáveis estritamente decoradas nas cores identitárias da Instituição (amarelo, azul, branco e laranja). O conjunto é fortemente persuasivo e exprime apelação emocional através da relação pais/filhos. As emoções despertadas através dos anúncios são intencionais e estão sempre apoiadas em crenças, valores e práticas sociais.

\section{A emoção na análise do discurso}

Segundo Sodré (2006), o termo emoção deriva do latim emovere, emotus, refere-se ao movimento energético ou espiritual em direção ao outro, capaz de afetar organicamente o corpo humano. Desta forma, Emotus significa então abalado, sacudido, posto em movimento. A emoção, colocada em cena pelo orador pressupõe a presença do receptor no discurso, para, assim afetá-lo de alguma maneira.

\section{Anúncio “Colo"}

A fotografia deste anúncio foi feita sob ângulo frontal com o enquadramento médio fechado, o que infere uma relação de proximidade, afinidade entre a personagem da foto e o espectador, quando ao mesmo tempo transmite seu estado de espírito. É composto por 
uma criança com faixa etária aproximada de dez a doze anos, trajada com um vestido branco com estampagem floral laranja com bolas nas extremidades. A imagem foca uma garota de pele e olhos claros, confortavelmente reclinada em uma rede, sob uma luz alaranjada e difusa, típica do período vesperal, uma brisa suave que é percebida pelo movimento dos seus cabelos louros e compridos. O conjunto representa o ícone do público para o qual o anuncio é direcionado, pessoas de classe média/alta, consumidores predominantes no seguimento pessoal da seguradora.

A imagem de uma criança, em primeiro plano, do sexo feminino, com um olhar direto para a câmera, sorriso singelo e um brilho nos olhos transmite a pureza e ingenuidade de um ser carente de cuidados e proteção. Isso somado a um texto de linguagem direta, em voz ativa com interjeições, curtas orações, superlativos e forte adjetivação, reforçam a ideia de canalizar a responsabilidade dos pais por garantirem a "segurança" dos filhos através do produto oferecido pelo banco.

O segundo plano é desfocado, mas com forte predominância da cor laranja com detalhes em azul escuro, não há moldura que delimite a imagem, o que permite liberdade ao imaginário de quem a observa. A diagramação foi organizada de forma a conduzir o olhar do consumidor, em primeira instância, às mensagens plásticas e icônicas simultaneamente, posteriormente o discurso é complementado com o seguinte texto, impresso com fontes brancas, e amarelas na ultima sentença, sobreposto na imagem: "Você não pode impedir que ela tenha medo do escuro. Você não pode impedir que ela caia da bicicleta. Você não pode impedir que ela tenha espinhas. Você não pode impedir que ela vá mal na escola. Você não pode impedir que ela não saiba que faculdade escolher. Você não pode impedir que ele chore por amor. Você não pode impedir que ela fique sem seu colo um dia. Mas você pode garantir que ela passe por tudo isso com mais segurança."

A repetição é um mecanismo automático de persuasão que age sobre a memória (LEDUC, 1977), muito utilizada na publicidade como técnica de fixação. No anuncio em questão foi explorada com maestria; a repetição da expressão "Você não pode impedir" sucedida por possíveis danos físicos e emocionais sofridos pela criança, invoca a interferência imediata do destinatário através da aquisição do produto que aparece como "a alternativa", a possível solução. O resultado foi uma mensagem bem argumentada e potencialmente patêmica.

No canto inferior direito, com fontes menores, estão os slogans da campanha: "Faça um Seguro Itaú de Vida. Tranquilidade para você, mais segurança para sua família”, que 
identifica o serviço oferecido, seguido com a logomarca e slogan do banco: "Itaú feito pra você”.

\section{Anúncio “Dupla Dinâmica”}

Nesta peça o personagem principal é um menino com faixa etária aproximada aos sete/oito anos, com o mesmo padrão de beleza do exemplo anterior: pele clara, olhos verdes e cabelos castanhos. Ele olha fixamente para a câmera com um sorriso largo nos lábios, veste uma camiseta e usa uma máscara, ambas de cor laranja, possui sobre as costas uma capa azul, onde completa o figurino que ao mesmo tempo em que indica um figurino de super herói remete as cores as quais identificam da agência. O padrão de beleza das crianças é o ícone utilizado para representar o público alvo e foi selecionado a partir dos padrões e estereótipo do mesmo; o que gera certa identificação e consequentemente aceitação da propaganda.

Sua formatação e diagramação seguem o mesmo perfil da peça anterior, o texto principal também, mas o direcionamento do discurso atenta aos desejos e medos que estão ligados crianças do sexo masculino: "Você não pode afirmar que ele não vai cair do muro e se machucar. Você não pode afirmar que ele vai superar os vilões que encontrar pelo caminho. Você não pode afirmar que ele terá o poder de salvar o planeta. Você não pode afirmar que uma cabine telefônica vai transformá-lo em um super herói. Você não pode afirmar que ele vai sempre terminar com a mocinha. Você não pode afirmar que vocês serão sempre uma dupla dinâmica. Mas você pode garantir que ele passe por tudo isso com mais segurança."

Tratando-se de um serviço criado preferencialmente para adultos de classe média alta o endereçamento não é direto, ou seja, nos casos acima, os anúncios utilizam-se dos filhos para "atingirem" os pais por intermédio do afeto presente na relação familiar, estratégia que reforça o efeito patêmico no público alvo.

\section{Modos de Organização do Discurso em agenciamento de emoções}

O serviço Seguro de Vida não ocupa posição prioritária no planejamento financeiro da grande massa social, as seguradoras de automóveis têm faturamento bem mais expressivo que os seguros de vida, como apontam dados da Sincor - Sindicato dos Corretores de Seguros do Estado de São Paulo, considerando que apenas $47 \%$ da 
população tem carro (IBGE 2010), constata-se que o alvo da campanha publicitária do Itaú é o público restrito às classes financeiramente estáveis. Para atingi-los a agência DM9DDB investiu em discursos patêmicos que persuadem por vias de emoção, influência e proposições de probabilidade. O efeito persuasivo dos anúncios pode ser melhor compreendido a partir de um estudo sobre Modos de Organização do Discurso (M.O.D.) postulados por Charaudeau (2008), através dos quais é possível ordenar determinadas finalidades discursivas no ato da comunicação, são eles: enunciativo, descritivo, narrativo e argumentativo.

Foram trabalhados os modos enunciativo e argumentativo no estudo das peças publicitárias do Itaú.

\section{Modo Enunciativo}

O M.O.D. enunciativo permite interpretar a posição assumida pelo enunciador em relação ao destinatário, ao dito e ao mundo. Assim, é possível traçar a relação de influência existente entre ambos bem como a maneira pela qual o sujeito falante conduz a encenação do ato comunicativo. Para Charaudeau o M.O.D. enunciativo é dirigido por três funções descritas abaixo:

Alocutiva: consolida-se uma relação de influência entre Sujeito Comunicante (SC) e Sujeito Interpretante (SI), pois o SI é conduzido, pelo ato de linguagem do SC, a exprimir uma determinada resposta ou reação. $\mathrm{O}$ discurso patêmico é patente.

Elocutiva: há a revelação do SC, este enuncia seu ponto de vista sobre o mundo, propósito referencial, independente da posição do SI. Tais Propósitos podem ser percebidos de acordo com as especificações, intrínsecas aos atos de linguagens, de modos de saber, de avaliações e/ou apreciações, de motivação, de engajamento e de decisão. (CHARAUDEAU, 2008).

Delocutiva: Caracteriza-se pela neutralidade do Enunciador baseado no discurso de um terceiro. Tal relação acaba por suprimir a efetividade SC com seu ato enunciativo e traços de subjetividade o que resulta numa não implicação do SI. Assim, pode-se estabelecer a seguinte configuração para o propósito dessa enunciação: Como no caso das asserções de "evidência" e "probabilidade", o propósito é imposto autonomamente por é um discurso pré-estabelecido, onde o Enunciador relata "o que o outro diz e como o outro diz". 
É visível que, nos anúncios trabalhados, o modo de organização Enunciativo é explorado em sua plenitude de funções. O texto principal é predominantemente delocutivo, o enunciador dá voz às probabilidades, em uma narrativa imparcial infere ao alocutário uma série de eventualidades desagradáveis passíveis de serem acometidas ao(s) filho(s) do mesmo. Para amplificar o apelo emocional latente nos enunciados foram utilizados personagens de ambos os sexos para personificar irrestritamente a lembrança do ente querido.

$\mathrm{Na}$ última sentença do texto, "Mas você pode garantir que ele passe por tudo isso com mais segurança.", caracteriza-se o a função elocutiva, momento em que o enunciador posiciona-se ante a discussão anteriormente levantada propondo ao alocutário uma possibilidade de intervenção ou atenuação dos dissabores ordinários a vida de uma um filho em suas relações consigo com os pais e com o mundo, possibilidade esta que não é, por hora, esclarecida.

No desfecho da mensagem linguística, que acompanha a logo e slogan do Itaú, o enunciador assume a função alocutiva, pois ao revelar "a intervenção" passível ao sujeito interpretante $(\mathrm{O}$ seguro de Vida Itaú, serviço dito promotor de tranquilidade e segurança para a família) impõe-lhe, sob voz imperativa, uma proposição própria não intenção evidente de influenciar e persuadir o público. Vale ainda salientar o emprego constante do pronome você, modo sutil de pincelar uma relação de afinidade entre os interlocutores do ato comunicativo.

\section{0 modo argumentatiuo}

O modo argumentativo também foi articulado nas peças publicitárias, este por sua vez, consiste em explicar determinado fato ao sujeito interpretante. Segundo Charaudeau (2008) o ato argumentativo compõe-se de três elementos: uma proposta sobre o mundo, um sujeito argumentante (locutor) e um sujeito-alvo, (interlocutor).

Diz o autor que argumentar é uma atividade discursiva que, do ponto de vista do sujeito argumentante, busca duas coisas: racionalidade e influência, o que caracteriza seu ideal de persuasão. O discurso racionalista conduz boa parte da mensagem linguística dos anúncios, pois o sujeito argumentante (SA) busca estabelecer verdades quanto à explicação de fenômenos do universo por ele percebidos através de suas experiências sociais ou individuais. Observe: 
Quando o SA diz: "Você não pode afirmar que uma cabine telefônica vai transformá-lo em um super herói" ou "Você não pode impedir que ela chore por amor", ele explicita sua noção de verdade adquirida, noção que não confere veracidade ao mundo fantasioso nem admite a manipulação das manifestações sentimentais.

A influência, por sua vez, compreende ideal persuasivo, consiste em compartilhar com o interlocutor determinado âmbito discursivo até que esse interlocutor adote as mesmas propostas. A busca da influência admite o uso de estereótipos e opiniões admitidas causadoras de um efeito de evidência.

Os traços de influência são desenhados nos anúncios pela interseção das mensagens visuais e linguísticas. O SA expõe suas proposições de "verdade adquirida" que denunciam limitações evidenciais do interpretante ante as infelicidades passíveis aos personagens dos quadros que são associados à figural filial. As imagens de crianças felizes, saudáveis e em um lugar aparentemente seguro, sugerem ao alocutário a posição de felicidade que ele pode proporcionar ao seu ente querido. Assim se configura por nova perspectiva o efeito patêmico.

\section{0 uso das imagens na fabricação da emoção}

Roland Barthes (1990) diz que se a imagem contém signos, é certo que em publicidade esses signos são plenos e formados com vista a uma melhor leitura, sendo assim, a imagem publicitária é franca ou pelo menos enfática. O publicitário, no processo de criação de objetos, marcas e imagens publicitárias visam à criação intencional destinada a um público-alvo que possa acreditar em algo, para tanto, deve buscar argumentação eficaz em sua discursiva.

Em uma análise discursiva dos dois anúncios, percebe-se através das mensagens plásticas, compostas pelas formas, iluminação e, principalmente, as cores a forte identificação e afirmação da agência bancária. Considerando a mensagem linguística, verificam-se as funções de fixação, como suporte para complementar a imagem.

(...) em publicidade, a significação da imagem é, certamente, intencional: são certos atributos do produto que formam a priori os significados da mensagem publicitária, e estes significados devem ser transmitidos tão claramente quanto possível; se a imagem contém signos, teremos certeza que, em publicidade, esses signos são plenos, formados com vistas a uma melhor leitura: a mensagem publicitária é franca, ou pelo menos enfática. (BARTHES, 1990, p. 28). 
As mensagens presentes nos textos e nas imagens são agenciadas de forma tal que conferem uma importância transcendente a representação do produto oferecido que assume posição tão essencial e inevitável quanto às ocasionalidades do cotidiano, nesse sentido MONNERAT adverte:

Estamos constantemente sendo submetidos a uma avalanche de produtos que pouco, ou quase nada, significariam para nós se não fosse a auréola que a publicidade lhes confere. Valendo-se do poder das palavras, ela garante a esses objetos um status especial, mitificando-os: um relógio pode transformar-se em uma joia; um carro, em símbolo de prestígio etc. (MONNERAT, 2003, p. 40).

\section{Considerações finais}

Vale ainda salientar que os anúncios, assim como toda propaganda, foram criados para persuadir e para isso, se utilizam de efeitos patêmicos apenas como uma ferramenta para tal objetivo, sendo assim o consumo deve ser algo saudável e responsável. O fato é que a imagem, em toda sua composição, não passa de mera encenação sendo que existem coisas muito mais sérias que sugerem uma atenção emotiva:

A questão não é propor uma insensibilidade generalizada, mas chamar a atenção para o excesso de efeitos patêmicos, produzidos em vários setores da sociedade ao tratar destes assuntos. 'Emocionar-se' por estas questões está na moda e é esse o problema: as modas passam. A moda esvazia os sentidos e o excesso dos efeitos patêmicos, das dramatizações, podem tirar do foco questões sérias e as colocarem para escanteio... (MENDES, 2008, p 20).

Contata-se assim a necessidade de um desenvolvimento senso crítico quanto ao poder de persuasão da publicidade bem como tantos outros seguimentos midiático, político-sociais que, por vias psicológicas, persuadem com a pregação de discursos condicionantes capazes de interferir efetivamente nas necessidades e escolhas do público.

\section{Referências Bibliográficas}

BARTHES, R. “A retórica da imagem”, In: O óbvio e o obtuso. Rio de Janeiro: Nova Fronteira, 1990. 
CHARAUDEAU, Patrick. Linguagem e discurso: modos de organização. São Paulo: Contexto, 2008.

JOLY, Martine. Introdução a Análise da imagem. Campinas: São Paulo: Papirus, 1996.

LEDUC, Robert. Propaganda: uma força a serviço da empresa. São Paulo: Atlas, 1977.

MENDES, E.; MACHADO, Ida Lúcia (Orgs.). As emoções no discurso. vol II. Campinas: Mercado de Letras, 2010.

MONNERAT, Rosane Mauro. A publicidade pelo avesso: propaganda e publicidade, ideologias e mitos e a expressão da ideia: o processo de criação da palavra publicitária. Niterói: Editora EdUff, 2003.

http://aporrada.com.br/v2011/2010/12/10/ibge-populacao-que-usa-carro-cresce-e-atinge47-em-2009/

http://www1.folha.uol.com.br/folha/dinheiro/ult91u631939.shtml

http://www.dm9ddb.com.br/?p=662

http://www.bocc.uff.br/pag/monteiro-adriana-emocao-discurso.pdf

http://www.uff.br/ensaiosdemarketing/artigos\%20pdf/1/artigooito.pdf

http://www.tudosobreseguros.org.br/sws/portal/pagina.php?l=228

http://lapecpp.files.wordpress.com/2011/05/bruna-g-crispim-tfg-final.pdf 


\section{AREKOS}

\section{Anexo 1: Anúncio "Colo" criado para campanha do seguro de vida do Itaú}

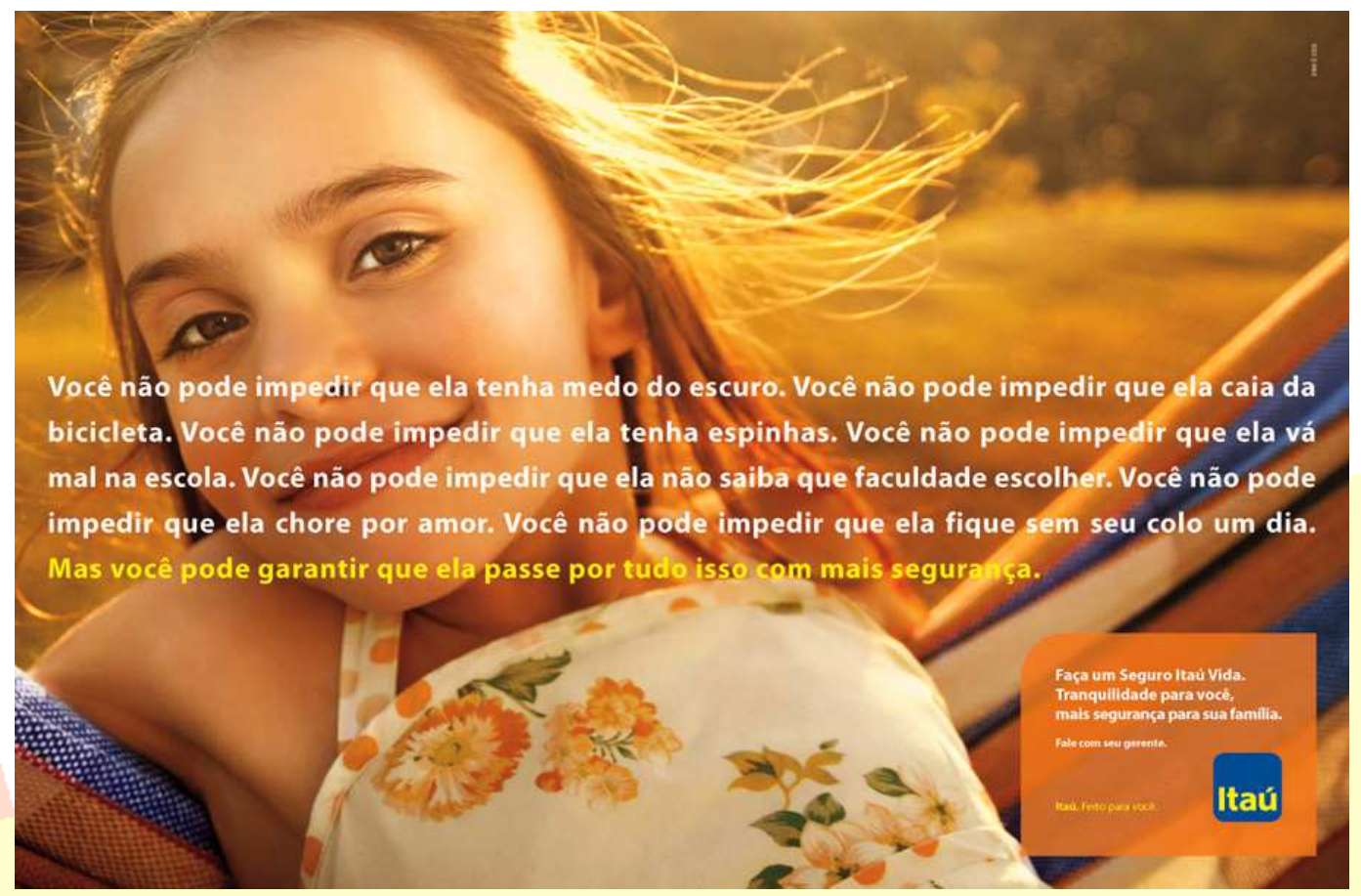

Anexo 2: Anúncio “Dupla Dinâmica”, peça da mesma campanha.

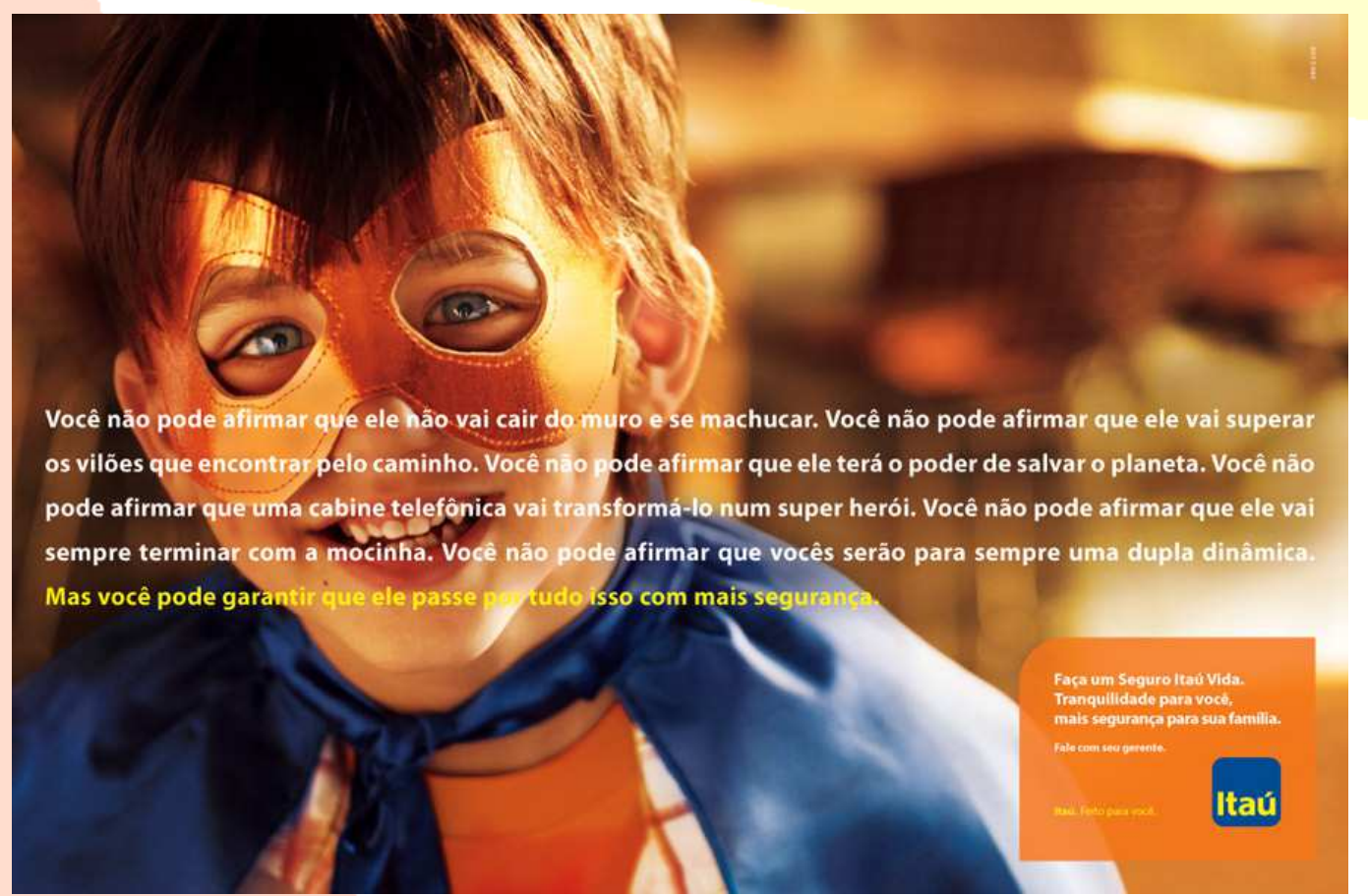

Reuista Anagrama: Reuista Científica Interdisciplinar da Graduação

$$
\text { Ano } 5 \text { - Edição } 3 \text { Março-Maio } 2012
$$

Auenida Professor Lúcio martins Rodrigues, 4Ч३, Cidade Uniuersitária, São Paulo, CEP: 05508-900 